\title{
The Impact of Fluoride in Drinking Water, on Oral Health and Skeletal System of School Children.
}

\author{
Dr. S. Meenakumari. DNB (Pediatrics), Dr. Girija Mohan,MD, \\ Dr. Sreelatha.MD, Dr. N. Retnakumari. MDS. M.Phil
}

\begin{abstract}
Modern life styles even among people in rural areas have created an increased demand for dental cosmetology. Dental fluorosis due to its cosmetic effect gains more public health importance today. In the scenario of increasing awareness of environmental health hazards, among people, the research into the biology of fluorosis conducted in the endemic area could be helpful to prove with evidence that fluoride in drinking water causes health hazards like dental and skeletal fluorosis, and also non skeletal manifestation of the disease 1,2,3. The problem has reached alarming proportions affecting at least 17 States in India. ${ }^{4}$. Of the fourteen Revenue Districts in Kerala, two districts, Alappuzha and Palakkad are endemic for fluorosis. A study was conducted in Alappuzha district and in Kollam, a nearby district, a non endemic area for the fluorosis, to assess and compare the various effects of fluoride in drinking water, on dental and skeletal systems of school children. The present study was conducted among 706 children of 9-12 year age group and sub samples of water collected from these areas for fluoride estimation. Results:The prevalence of dental fluorosis in the endemic region $66.4 \%$ where as it was nil in the non endemic region. The results also indicated that the level of fluorosis could be graded in respect of children of as : $14.8 \%$ grade I; $41.1 \%$ grade II; $10.3 \%$ grade III and $0.2 \%$ grade IV. Dental fluorosis. There was a statistically significant $(p=0.000)$ association between fluoride level in the water and dental fluorosis. It was found that nearly one third of the children clinically examined for the study had non specific symptoms of skeletal fluorosis in Alapuzha district. This association was found to be statistically significant $\left(\chi^{2}=7.99, \quad P\right.$ value $\left.=.0 .018\right)$. The prevalence of nonspecific symptoms like, backache 3.8\%; neck pain 16\% and history of skeletal fracture $12.1 \%$ was observed among the children in Alappuzha district, where as all these symptoms were observed only among $1 \%$ of children of Kollam district,non endemic area. The prevalence of dental fluorosis and non specific symptoms of skeletal fluorosis was high among the school children in the district endemic fluorosis.
\end{abstract}

Key Words: Dental fluorosis, Skeletal fluorosis, Endemic area, Enviornmental Health Hazard

\section{Introduction}

In the scenario of increasing awareness of environmental health hazards, among people, the research into the biology of fluorosis conducted in the endemic area could be helpful to prove with evidence that fluoride in drinking water causes health hazards like dental and skeletal fluorosis, and also non skeletal manifestation of the disease. Modern life styles even among people in rural areas have created an increased demand for dental cosmetology. Dental fluorosis due to its cosmetic effect gains more public health importance today. The period of greatest susceptibility being at the time of mineralization of permanent teeth, continuous residents of the areas covered, were chosen for the study than migrants $t$ areas ${ }^{4,5}$

The problem has reached alarming proportions affecting at least 17 States in India. There are 50-100\% revenue districts affected in Andhra Pradesh, Tamil Nadu, Uttar Pradesh, Gujarat, Rajasthan and 30-50 \% districts in Bihar, Haryana, Karnataka, Maharashtra, Madhya Pradesh, Punjab, Orissa, West Bengal and less than $30 \%$ districts in Jammu and Kashmir, Delhi, and Kerala. ${ }^{3,6}$.

Of the fourteen districts in Kerala, two districts, Alappuzha and Palakkad, are considered endemic for fluorosis. Prevalence of $36 \%$ of dental fluorosis has been reported in Alappuzha (Gopalakrishnan et al in 1999). ${ }^{7}$. Though skeletal fluorosis has not been reported so far from the Kerala State there has been increasing reports of various manifestations of non skeletal fluorosis like fatigue, vague abdominal discomfort, dyspepsia etc. Perhaps the symptoms of skeletal fluorosis may begin from the childhood in a nonspecific manner, and later progress to frank skeletal fluorosis of adulthood.

There have been no consolidated studies so far in Kerala, which stands first in literacy among the states in India, to determine the prevalence of skeletal fluorosis in the pediatric age group. In this setting, a comparative study was conducted in Alappuzha district, an endemic area for fluorosis, and in Kollam, a nearby district, a non endemic area for the fluorosis, to assess and compare the various effects of fluoride in drinking water, on dental and skeletal systems of school children.

The two adjacent districts - Alappuzha and Kollam - were considered to be ideal for assessing the impact of fluoride in drinking water on dental and skeletal tissues. These two adjacent districts included in the 
study are appropriate for a comparative analysis in every aspect in socio-economic and demographical and geographical features (both coastal areas) except in water fluoride levels. This type of a comparative study is the first of its kind in the State of Kerala.

\section{Objectives}

Objectives of the current study are listed below:

1. To assess the prevalence of dental fluorosis among school children in Alappuzha and to compare the results with its prevalence among school children of Kollam ;

2. To associate the relation between the levels of fluoride in drinking water and dental health;

3. To determine the risk factors, if any, associated with the dental fluorosis, apart from fluoride in drinking water; and

4. To investigate the prevalence of non specific skeletal symptoms, which could be an early manifestation of skeletal fluorosis.

\section{Materials And Methods}

Study design

Cross sectional analysis was designed to attain the objectives set for the study.

\section{Setting of the study}

This community based study was carried out in five schools of Alappuzha district and two schools at Kollam district of Kerala State. Both aided and unaided schools were selected for the study. Children of high income strata mostly studying in unaided schools and children of low income strata in the aided schools were selected for the study. The sample frame facilitated the required data for the comparison of socio economic class and the assessment of impact of fluoride in drinking water.

\section{Participants}

School children between the age group of 9 to 12 years -both inclusive - were covered under the sample for the study. The children chosen for the study were continuously residing in the specified areas since they were born. For this purpose, it was individually verified whether each child was considered for investigation was born and living in that area excepting for a short interval such as during school vacations. This means the child has been exposed to the drinking water with the particular level of fluoride characteristics of the area from birth through childhood and spent nearly all his/her time in the respective area till date.

\section{Sample frame}

Cluster sampling method was adopted for the study. Five schools were selected from Alappuzha district, based on more concentration of fluoride in the drinking water in the surrounding areas compared to the normal level. The schools selected were Aryad UPS, Chettikadu UPS, Thiruvambadi UPS, Lutheran school and Bright land school. In order to compare the results of the examination in respect of the children selected from these five schools from Alappuzha district, two schools from the adjacent Kollam district were also chosen for the study. The schools selected from Kollam districts were Government Model High School, Kollam, Town UPS and LPS West Kollam. These schools were selected on judgement sample method. There were 15080 primary school children in twenty five schools located in Ambalappuzha taluk in Alappuzha district where the fluoride content in drinking water is higher than normal level. Simple Random sampling by lot method was adopted to choose the schools for the study. All the upper primary school children, who satisfied the condition of continuous residential status mentioned earlier in the selected clusters were examined for the study. In all the selected schools there were mixed population of both the genders.

In the beginning of the survey, intra examiner variability was measured by carrying out reproducibility. A group of children were examined twice and the results of these two examinations were subjected to comparison and an acceptable consistency of 90 percent agreement was observed..

Two separate interview schedules were developed for the study. The first set of questionnaire was used for recording the clinical observations and the level of fluoride in drinking water, and the other for ascertaining the effect there of on dental and skeletal fluorosis among the school children from Alappuzha district (GroupA) and Kollam district (Group B).

The prevalence of dental fluorosis in Alappuzha district was reported to be $35.2 \%$. Setting the prevalence of dental fluorosis as $30 \%$, the sample size was calculated for cluster sampling method.

Final sample size was calculated as 506 for the group A and 200 for the group B. Sub samples were selected randomly for estimation of fluoride in drinking water. From the group A 36 water samples and from the group B 15 water samples were collected for fluoride estimation. Simple random sampling method was used for selecting the samples for fluoride estimation. 


\section{Data Collection}

The present study was conducted at the Department of Pediatrics, Medical College, Alappuzha with the collaboration of Department of Pedodontics, Government Dental College, Trivandrum. With the prior permission obtained from the Institutional Ethical Committee and school authorities, the researcher visited the specified schools on the stipulated days. General examination was carried out and data related to variables such as gait, speech and intelligence based on average school performance results, were recorded. Then the children were examined for ascertaining the symptoms of skeletal fluorosis such as back ache, neck pain, paraesthesia , numbness, stiffness of joints, joint deformities, muscle wasting and neurological defect. Intra oral examination was carried out by using the mouth mirror and explorer in good natural day light for assessing the presence enamel mottling, dental fluorosis by adopting Deans index.Dental caries status of each child was also recorded using decayed, missing \& filled tooth (DMFT) to correlate with fluoride in water.

All the children were examined categorizing group A and group B.

\section{Estimation of fluoride in drinking water}

In the second phase, estimation of fluoride in drinking water was done. Water samples were collected from the selected sub sample of children covered in group A and group B separately. The fluoride estimation was done with the support and guidance of Quality Control Regional Laboratory, Water Authority Department of Government of Kerala, at Kawdiar Thiruvananthapuram. The water fluoride was quantitatively analysed employing SPADNS Calorimetric method.

The SPADNS (Sodium 2- parasulfophenylazo, 1, 8 dihydroxy - 3,6 naphthalene disulphuric acid). Calorimetric method is based on the reaction between fluoride and zirconyl acid. As the fluoride concentration increases, colour of the reagent becomes progressively lighter.

\section{Analysis of data}

Analysis of the data collected by examining 706 school children (506 in the Group A and 200 in the Group B) between 9 and-12 years in five schools of Alappuzha district and two schools of Kollam district in Kerala was made as given below.

\section{Profile}

The baseline characteristics of the group A according to sex, age, location, type of food habits, main food item in house, were analyzed. The variables like consumption of black tea, citrus fruits, sea fish, dry fish, main source of drinking water, were taken into consideration.

The male female distribution ratio in the Group A was almost equal (52.2\% and 47.8\%). It was observed that $50.4 \%$ of the Group A used black tea daily. It is also worth mentioning that $99 \%$ respondents were consuming rice as main food items with non vegetarian habit..The sea fish formed a major item in the food either daily or occasionally. The main source of drinking water in Group A was pipe water (73.5\%). Food habit was almost the same compared to group A excepting in the consumption of drinking water. The group A dependant more on pipe water where as in group B dependence of drinking water fell almost equally on pipe water and well water.

Majority of the respondents belonged to nuclear family (57.5\% of group A and $65.5 \%$ of group B). The parents of only $26.4 \%$ children of group A had educational qualification of graduation and above however wide variation is not seen among the parents of both the groups with respect to educational status. It was also attempted in the present to examine the oral hygiene practices, such as the mode of cleaning teeth, frequency, and material used for cleaning.

Almost all the children used tooth brush (90.5\% of Group A and 95\% of Group B) for cleaning the teeth, $83.6 \%$ of the children of Group A and $93.5 \%$ of Group B were using the fluoridated tooth paste for brushing. Unlike other parts of the country, it has been a common practice in Kerala that all most all people irrespective of their age and economic status, use the brush, paste for cleaning the tooth at least once in a day.

The Gait and Speech almost all the children under review were normal in both the groups. The intelligence of the children was also above average in both the groups based on the positive performance in the results school examinations $(97.8 \%$ in group A and $97 \%$ in group B). There was no statistically significant difference found between the children of Group A and Group B in respect of this variable considered for the current study. Neither significant illness nor vitamin deficiency was observed among the children in any of the two groups under review.

\section{Oral examination}

The oral examination variables taken into consideration for the study were oral hygiene status, gingival status and dental caries status using DMFT (decayed, missing, filled tooth) criteria. 
In respect of oral hygiene status it was observed that a large portion of the children examined for the study were at the moderate level or above in both the groups. However in respect of gingival status children from group A were observed to be in a better state compared to children from group B. This difference was also found to be statistically significant.

It was also attempted in assessing the prevalence caries among the school children examined. It was observed that the prevalence of caries in group A was $29.1 \%$ where it was $52.5 \%$ in group B. The difference is found to be statistically significant indicating that the children in group B are vulnerable to dental caries.

\section{Dental flourosis}

The attempt to estimate the level of fluorosis among the children covered under the current study has brought about notable facts. Out of 506 children examined in Group A, 336 children had dental fluorosis. The prevalence of dental fluorosis in group A was $66.4 \%$. In group B out of 200 children clinically examined, dental fluorosis was observed not even in a single child. (Table 1)The results also indicated that the level of fluorosis could be graded in respect of children of group A : 14.8\% grade I; $41.1 \%$ grade II; $10.3 \%$ grade III and $0.2 \%$ grade IV.(Chart 1) Dental fluorosis grading was done according to Deans criteria. It was also observed that grade III and IV categories had caused discolouration of teeth, that is enamel hypoplasia probably occurred due to the consumption of water containing high level fluoride during early childhood.(Table 2). This disclouration was found to be statistically significant among the children of group A and B. Besides discolouration of teeth, white spots in a varied manner, which are considered to be mild level fluorosis, were observed in teeth among all the children affected by fluorosis. The association of white spots teeth in was also found statistically significant. Mottling and pitting teeth which are considered to be early signs of severe fluorosis were also observed.(Table 3 )

\section{Skeletal Fluorosis}

The symptoms of skeletal fluorosis include backache and neck pain. Taking into account this fact, the history of skeletal fractures among the children covered under the study were investigated with a view to ascertaining the probable existence of skeletal fluorosis. The results of such an investigation is presented in Table 4.

The symptoms of skeletal fluorosis, like backache, neck pain and skeletal fracture were found to be higher in children of Group A compared to the children in Group B and this observation is found to be statistically significant. (Pvalue <.01). The prevalence of backache was $3.8 \%$, neck pain $16 \%$ and history of skeletal fracture $12.1 \%$ in group A, where as in all these three variables, these symptoms were observed were $1 \%$ group B. The nonspecific skeletal symptoms were observed in $27.3 \%$ children of the Group A. This association was found to be statistically significant in comparison with the children of group B. (Chart 2)

\section{Association between level of fluoride in water and selected variables}

Association between water fluoride level and prevalence and severity of dental fluorosis was analysed, by collecting water samples from the subsamples of Group A (36) and Group B (15). When the water fluoride level was less than 1ppm, (16) 84.2\% had no evidence of dental fluorosis. All children of the Group B had water fluoride level less than $1 \mathrm{ppm}$. Majority of children with moderate dental fluorosis consumed water of fluoride level more than $1.25 \mathrm{ppm}$. The results showed a statistically significant $(\mathrm{p}=0.000)$ association between fluoride level in the water and dental fluorosis. (Table 5).

The association of non specific symptoms of skeletal fluorosis and water fluoride level of selected sub sample were also analysed. It was found that about one third of the children clinically examined for the study had non specific symptoms that may lead to skeletal fluorosis. This association was statistically significant ( $\chi^{2}=7.99, \mathrm{P}$ value $\left.=.0 .018\right)($ Table 6$)$.

\section{Association of fluorosis with socio-demographic variables}

The association of prevalence of dental fluorosis on variables in respect of location of residence, gender and sex was evaluated. It was found that there was no significant association between prevalence of dental flourosis and locale, gender and age (Table 7). The association between Dental Fluorosis among children in group A and selected variables such as age, type of food, source of drinking water, type of water, daily consumption of water in glasses, use of black tea, use of sea fish, use of dry fish, and use of citrus fruits were also examined. The results showed statistically significant association between dental fluorosis and the main source of drinking water -pipe water. $\left(\chi^{2}=13.12\right.$, P value $\left.=0.000\right)$. In respect of other variables, such as age, type of food, daily consumption of water, type of water and use of sea fish, dry fish, use of citrus fruits,no significant association was found. (Table 8)

It was further analysed whether there existed positive association between dental fluorosis and source of drinking water. The results indicated that significant association existed between pipe water and dental 
fluorosis. $\left(\chi^{2}=29.30, \mathrm{p}\right.$ value $\left.=.004\right)$, The source of water referred to as others in Table 9 was mainly water kept in pots and other such devises as drinking water for children in schools. In most of the cases this was taken from the public tap installed by the authorities of local bodies and there is every possibility for its influence in causing fluorosis to the users. It was observed only in rare cases that this source formed draw well water and bore well water.

\section{Discussion}

In the scenario of increasing awareness of environmental health hazards, among people, the research into the biology of fluorosis conducted in the endemic area of Alappuzha district was helpful to prove with evidence that fluoride in drinking water causes health hazards like dental and skeletal fluorosis, and also non skeletal manifestation of the disease. Modern life styles even among people in rural areas have created an increased demand for dental cosmetology. Dental fluorosis due to its cosmetic effect gains more public health importance today. The period of greatest susceptibility being at the time of mineralization of permanent teeth, continuous residents of the areas covered, were chosen for the study than migrants to that areas. The two adjacent districts - Alappuzha and Kollam were considered to be ideal for assessing the impact of fluoride in drinking water on dental and skeletal tissues. These two adjacent districts included in the study were appropriate for a comparative analysis in every aspect in socio-economic and demographical and geographical features (both coastal areas) excepting water fluoride levels. This type of a comparative study is the first of its kind in the State of Kerala. The mean age distribution of 9 to 12 years was taken to assess the effect of fluoride in permanent dentition.

\section{Prevalence of dental fluorosis}

The prevalence of dental fluorosis in Group A (Alappuzha) was as high as $66.4 \%$ whereas it was nil in Group B (Kollam). It depicts that dental fluorosis is a major public health problem in Alappuzha. The study conducted in Alappuzha by Gopalakrishnan et al ${ }^{7}$, concluded prevalence level of $35.6 \%$. The prevalence of dental fluorosis was found to substantially higher in the present study, compared to the observations of the previous study, which suggests that fluorosis is a major problem in the study area. The fluoride levels of pipe water in general supply have now increased to a mean of $1.8 \mathrm{ppm}$ in the taluk under study when compared to 1.4 ppm as revealed in the previous study held 10 years back. Stepwise increase in the prevalence of dental fluorosis corresponding to the increase in the level of fluoride was also observed in the present study. It is pertinent to mention in this connection the study results of Chandrashekar J, and Anuradha KP ${ }^{8}$ who assessed the prevalence and severity of dental fluorosis and its relationship with fluoride levels in drinking water and observed that there was a stepwise increase in the prevalence of dental fluorosis with corresponding increase in water fluoride content, and a significant positive linear correlation $(r=0.99)$ between CFI and water fluoride level. Thus observation is fully in conformity with the findings of the current study.

\section{Risk factors for dental fluorosis Source of water}

Pipe water was the single most independent risk factor for dental fluorosis when association between water fluoride level and severity of dental fluorosis was considered for review. There was a positive association between dental fluorosis and source of water $(\mathrm{P}$ value $=0.004)$ found among the children in Alappuzha district (endemic area).This observation becomes more reliable while taking into consideration the finding that not even a single child from the Kollam district ( non endemic area), where the water fluoride level was less than 1 ppm, was adversely affected by dental fluorosis.. The current study was carried out in the urban and rural areas of Ambalappuzha Taluk of Alappuzha district, wherein locale related differences in the prevalence of dental fluorosis could not be observed. $(p=0.864)$, in contrast to the findings of Gopalakrishnan et al ${ }^{7}$, where the prevalence was higher in the urban areas. In the early years, in rural areas, the major source of drinking water was surface water-pond and well water- and in urban areas pipe water. The improvisation of water supply facilities, both in the rural and urban areas, with the initative of local bodies, has led to wide spread dependence on pipe water, for drinking purpose. The direct consumption of pipe water through public water supply system by the people of urban and rural areas could be instrumental in discarding the locale related differences. Pipe water has high flouride content and as such, the possibility is that the locality difference of the dental fluorosis is getting vanished.

\section{Age}

Age wise difference in the prevalence of dental fluorosis among the children studied was found to be insignificant. Among all the age groups, the prevalence of grade II dental fluorosis was higher. This finding corroborates with the observation of the study conducted earlier in the district by GopalaKrishnan etal ${ }^{7 .}$ 


\section{Locale}

The current study was carried out in the urban and rural areas of Ambalappuzha Taluk of Alappuzha district, wherein locale related differences in the prevalence of dental fluorosis could not be observed. $(p=0.864)$, in contrast to the findings of Gopalakrishnan et $a{ }^{7}{ }^{7}$ where the prevalence was higher in the urban areas. In the early years, in rural areas, the major source of drinking water was surface water-pond and well water- and in urban areas pipe water. The improvisation of water supply facilities, both in the rural and urban areas, with the initative of local bodies, has led to wide spread dependence on pipe water, for drinking purpose. The direct consumption of pipe water through public water supply system by the people of urban and rural areas could be instrumental in discarding the locale related differences. Pipe water has high flouride content and as such, the possibility is that the locality difference of the dental fluorosis is getting vanished.

\section{Gender}

In the present study no significant gender difference could be noted in relation to the prevalence fluorosis. Other factors like parental education and related socio economic status did not show a significant association with the prevalence of dental fluorosis. Use of fluoride containing toothpaste also did not exert a significant effect on the development of dental fluorosis.

\section{Food habits}

There was no positive relationship found between the prevalence fluorosis and the consumption of food items such as, sea fish and dry fish among the children of Alappuzha District. There has been a high consumption of black tea, which has high fluoride content. However, significant association was not revealed with the prevalence of dental fluorosis and consumption of black tea,

\section{Dental fluorosis and dental caries}

It was observed that the prevalence of dental caries among the children of Alappuzha district was $29.1 \%$ where it was $52.5 \%$ among the children in Kollam district.. This difference is found to be statistically significant indicating that the children of kollam district are vulnerable to dental caries. This variation might be due to the anti cariogenic effect of fluoride in drinking water that has favourably acted among the children of Alappuzha district. This is in agreement to the results obtained in various studies conducted earlier that optimal water fluoride level has anti cariogenic effect. ${ }^{9}$ In India also this observation was reported by Baskaradoss JK, et al ${ }^{10}$ who viewed that $65 \%$ of the children with dental fluorosis had no caries, indicating the positive effects of fluoride. The prevalence of dental fluorosis was attributed to the level of fluoride in the drinking water as it exhibited a step-wise increase when the water fluoride levels increased from 1.5-1.7 ppm. Earlier research studies also have reported that if the child had lived in the endemic area during the period of calcification of teeth i.e. from birth to the age of 12-14 years, enamel mottling occurred. These teeth were found to be remarkably resistant to dental caries (Amarjit Singh et al ) ${ }^{11}$. The fluoride level of drinking water in these areas ranged from 2.00 to $14.00 \mathrm{ppm}$.

\section{Skeletal symptoms}

In other states of the India where fluorosis is endemic, concurrent existence of skeletal fluorosis is being highlighted. It requires special mention at this juncture that there has been no consolidated study so far conducted in the State of Kerala to assess the prevalence of skeletal fluorosis. Skeletal fluorosis is chiefly an adult disease. The study of prevalence of preclinical skeletal fluorosis in children has, thus, inherent limitations. Radiological examination as a part of routine screening was not feasible in the study group of school children for obvious reasons. However in the sample of Alappuzha district, the endemic area, 27.3\% of children had symptoms like backache, neck pain or history of occurrence of skeletal fracture $(\mathrm{p}=0.018)$. As mentioned earlier, the two adjacent districts selected for the study have identical features in social, demographical, geographical and economic factors with the only difference in the water fluoride levels. Since the symptoms could be the fore runner of skeletal fluorosis in adulthood, these children have to be followed up and skeletal examination conducted in adulthood, to establish a definite relation between water fluoride levels, non specific skeletal symptoms and full blown skeletal fluorosis. The age distribution of 9 to 12 years, was taken to assess the effect of fluoride in permanent dentition. ${ }^{12,13}$

\section{Association between fluoride level in water and severity of dental fluorosis.}

In the present study pipe water was the single most independent risk factor for dental fluorosis. When association between water fluoride level and severity of dental fluorosis was analysed, it was understood that no child in the non endemic area where the water fluoride level was less than 1ppm, was affected with dental fluorosis. The children among the sub sample in the endemic area Alappuzha, had dental fluorosis .Majority of 
children with moderate dental fluorosis in the sub sample of the study group consumed water with fluoride level more than $1.25 \mathrm{ppm}$.

\section{Summary \& Conclusions}

1.The prevalence of dental fluorosis in the endemic region was $66.4 \%$ where as it was nil in the non endemic region.

2. The level of fluorosis could be graded in respect of children of as : $14.8 \%$ grade I; $41.1 \%$ grade II; $\quad 10.3 \%$ grade III and $0.2 \%$ grade IV. Dental fluorosis. It was also observed that grade III and IV categories had caused discolouration of teeth, that is enamel hypoplasia probably occurred due to the consumption of water containing high level fluoride during early childhood.

3.There was a statistically significant $(\mathrm{p}=0.000)$ association between fluoride level in the water and dental fluorosis. The children who consumed drinking water containing fluoride level of less than $1 \mathrm{ppm}$ had no evidence of dental fluorosis. However when the level of fluoride increased from $1.25 \mathrm{ppm}$ majority of children were seen affected by moderate dental fluorosis. There were also stepwise increases in the grade of dental fluorosis corresponding to the increases in the level of fluoride in the drinking water.

4.The prevalence of dental fluorosis was higher in children who consumed pipe water, compared to children who consumed ground water. There existed a positive association between dental fluorosis and source of drinking water. The results thereof indicated that significant association existed between pipe water and dental fluorosis. $\quad\left(\chi^{2}=29.30, \mathrm{P}\right.$ value $\left.=.004\right)$.

5.The association of non specific symptoms of skeletal fluorosis and water fluoride level of selected sub sample were also analysed. It was found that about one third of the children clinically examined for the study had non specific symptoms that may lead to skeletal fluorosis. This association was statistically significant $\left(\chi^{2}=7.99, \mathrm{P}\right.$ value $=.0 .018)$

The current study was carried out in the urban and rural areas of Ambalappuzha Taluk of Alappuzha district, wherein locale related differences in the prevalence of dental fluorosis could not be observed. $(\mathrm{p}=0.864)$. This is mainly on account of the improvisation of water supply facilities, both in the rural and urban areas, with the initative of local bodies. The direct consumption of pipe water through public water supply system by the people of urban and rural areas could be instrumental in discarding the locale related differences.

\section{Suggestions}

Based on the observations and findings of the present study, the following suggestions are made:

\section{Prevention}

Methods of deflouridation recommended so far are aimed at bringing the fluoride levels to the WHO standards. Desirable characteristics of defluoridation process, are that it should be cost effective, easy to handle and operate by rural population, and is independent of input fluoride concentration, alkalinity, temperature; and does not affect taste of water, and does not require addition of other undesirable substances (e.g. Aluminium) to treated water.

Keeping in view the cost involved in defluoridating the water, it is desirable that the defluoridation of water should be restricted to drinking water. Periodic surveys are needed to monitor dental fluorosis and skeletal fluorosis.

\section{Creation of awareness}

General skeletal fluorosis directly affects the economy of the area under review by causing illness and debilitation not only in humans but also in their domestic animals, on which they may be depending for regular income. Hence, provision of defluoridated drinking water and health education aimed at abating fluorosis are highly desirable in the endemic regions. For the conditions prevailing in India as a whole Susheela, A.K ${ }^{14,15}$. suggested that in the Fluorosis Management Programme, the emphasis is on generating awareness among professionals, developing information, education, and communication packages, involving the community, and devising specific strategies for using the technology for fluoride removal and other approaches for providing safe water and consuming calcium, vitamin $\mathrm{C}$, and an antioxidant-rich diet on a sustainable basis .It is hoped that the findings of the present study also significantly expands the knowledge in the problem under investigation

\section{Implications of the present study}

The present study is aimed at providing an insight as a pointer to the public health physicians, dentists, chemists, planners, administrators, engineers and water supply authorities. The information furnished in this report can be utilized as preliminary data, and a well-designed epidemiological investigation can be undertaken at Taluk level and District level in the State as well as the National level. 
The Impact of Fluoride in Drinking Water, on Oral Health and Skeletal System of School Children.

VII. Tables

Table 1 : Prevalence of dental fluorosis among Group A and Group B

\begin{tabular}{|l|l|l|}
\hline Dental fluorosis & Group A & Group B \\
\hline Nil & $33.6 \%$ & $100 \%$ \\
\hline Grade I & $14.8 \%$ & 0 \\
\hline Grade II & $41.1 \%$ & 0 \\
\hline Grade III & $10.3 \%$ & 0 \\
\hline Grade IV & $0.2 \%$ & 0 \\
\hline
\end{tabular}

Table 2 : Comparison of No. of teeth with Yellow discolouration based on group

\begin{tabular}{|l|l|l|l|l|l|}
\hline Group & Mean & SD & N & T & P \\
\cline { 1 - 4 } Group A & 0.0 & 0.0 & 200 & \multirow{2}{*}{$3.39^{* *}$} & \multirow{2}{*}{0.001} \\
\hline Group B & 0.3 & 1.1 & 506 & \\
\hline
\end{tabular}

**significant at 0.01 level

Table 3: Comparison of No. of teeth with white spots based on group

\begin{tabular}{|l|l|l|l|l|l|}
\hline Group & Mean & SD & N & t & P \\
\cline { 1 - 4 } Group B & 0.0 & 0.0 & 200 & \multirow{2}{*}{$13.93 * *$} & \multirow{2}{*}{0.000} \\
\hline Group A & 8.7 & 8.8 & 506 & & \\
\hline
\end{tabular}

** : significant at 0.01 level

Table 4. Comparison of the existence of symptoms of skeletal fluorosis

\begin{tabular}{|l|l|l|l|l|l|}
\hline Variable & & Group A & Group B & $\chi^{2}$ & P \\
\hline \multirow{2}{*}{ Backache } & No & $96.2 \%$ & $99.5 \%$ & $5.52^{*}$ & 0.019 \\
\cline { 2 - 6 } & Yes & $3.8 \%$ & $0.5 \%$ & & \\
\hline \multirow{2}{*}{ Neck pain } & No & $84 \%$ & $100 \%$ & $36.17^{* *}$ & 0.000 \\
\cline { 2 - 7 } & Yes & $16 \%$ & 0 & & \\
\hline \multirow{2}{*}{ History of skeletal fracture } & No & $87.9 \%$ & $99.5 \%$ & & \\
\cline { 2 - 7 } & Yes & $12.1 \%$ & $0.5 \%$ & & 0.000 \\
\hline
\end{tabular}

Table 5 : Association between dental fluorosis and fluoride level in water

\begin{tabular}{|c|c|c|c|c|c|}
\hline Dental fluorosis & \multicolumn{4}{|c|}{ Fluoride level in water } & \multirow{3}{*}{$\mathbf{p}$} \\
\hline & Up to 1 & $1-1.25$ & $1.25-1.5$ & $1.5+$ & \\
\hline Nil & $84.2 \%$ & 0 & 0 & 0 & \\
\hline Grade I & $5.2 \%$ & 0 & 0 & 0 & \multirow{3}{*}{0.000} \\
\hline Grade II & $5.2 \%$ & $50 \%$ & $45.5 \%$ & $10.5 \%$ & \\
\hline Grade III+ & $5.2 \%$ & $50 \%$ & $54.5 \%$ & $89.5 \%$ & \\
\hline
\end{tabular}

** : significant at 0.01 level

Table 6: Association between flouride level in water and Skeletal symptoms

\begin{tabular}{|l|l|l|l|l|l|l|}
\hline \multirow{2}{*}{$\begin{array}{l}\text { Skeletal } \\
\text { fluorosis }\end{array}$} & Flouride level in water & \multicolumn{2}{|c|}{$\chi^{2}$} & $\mathrm{p}$ \\
\cline { 1 - 5 } & Upto 1 & $1-1.25$ & $1.1-1.5$ & $1.5+$ & & \\
\hline No & $68.4 \%$ & $100 \%$ & $54.5 \%$ & $57.8 \%$ & $0.018^{*}$ \\
\hline Yes & $31.6 \%$ & 0 & $45.5 \%$ & $42.2 \%$ & & \\
\hline
\end{tabular}

$*$ : significant at 0.05 level

Table 7 : Association between dental fluorosis and selected background variables

\begin{tabular}{|c|c|c|c|c|c|c|c|c|}
\hline & & \multicolumn{7}{|c|}{ Dental fluorosis } \\
\hline & & Nil & Grade I & Grade II & Grade III+ & All grades & $\chi^{2}$ & $\mathrm{P}$ \\
\hline \multirow{3}{*}{ Locale } & Urban & $33.3 \%$ & $15.6 \%$ & $38.5 \%$ & $12.5 \%$ & $66.7 \%$ & \multirow{3}{*}{2.54} & \multirow{3}{*}{0.864} \\
\hline & Semiurban & $31.6 \%$ & $17.9 \%$ & $39.3 \%$ & $11.1 \%$ & $68.4 \%$ & & \\
\hline & Rural & $4.5 \%$ & $13.3 \%$ & $42.7 \%$ & $9.6 \%$ & $65.5 \%$ & & \\
\hline \multirow{2}{*}{ Sex } & Male & $33.7 \%$ & $13.6 \%$ & $41.3 \%$ & $11.4 \%$ & $66.3 \%$ & \multirow{2}{*}{0.947} & \multirow{2}{*}{0.514} \\
\hline & Female & $33.5 \%$ & $16.1 \%$ & $40.9 \%$ & $9.5 \%$ & $66.5 \%$ & & \\
\hline \multirow{4}{*}{ Age } & 9 & $31.1 \%$ & $13.3 \%$ & $42.7 \%$ & $12.9 \%$ & $68.9 \%$ & \multirow{4}{*}{2.517} & \multirow{4}{*}{0.829} \\
\hline & 10 & $33.3 \%$ & $18.8 \%$ & $41.9 \%$ & $6 \%$ & $66.7 \%$ & & \\
\hline & 11 & $34.8 \%$ & $14.2 \%$ & $40.4 \%$ & $10.6 \%$ & $65.2 \%$ & & \\
\hline & 12 & $52.2 \%$ & $13 \%$ & $26.1 \%$ & $8.7 \%$ & $47.8 \%$ & & \\
\hline
\end{tabular}


The Impact of Fluoride in Drinking Water, on Oral Health and Skeletal System of School Children.

Table 8: Association between Dental Fluorosis and selected variables (for Group A only)

\begin{tabular}{|c|c|c|c|c|c|c|}
\hline \multicolumn{7}{|c|}{ Dental Fluorosis } \\
\hline \multirow[t]{2}{*}{ 1.Age } & \multicolumn{2}{|l|}{ No } & \multicolumn{2}{|l|}{ Yes } & \multirow[t]{2}{*}{$\chi^{2}$} & \multirow[t]{2}{*}{$P$} \\
\hline & Count & Percent & Count & Percent & & \\
\hline 9,10 & 70 & 31.1 & 14 & 58.3 & 0.74 & 0.391 \\
\hline 11 & 39 & 33.3 & 78 & 66.766 .8 & & \\
\hline 12 & 61 & 37.2 & 103 & 62.8 & & \\
\hline \multicolumn{7}{|l|}{ 2. Type of food } \\
\hline Vegetarian & 10 & 41.7 & 14 & 58.3 & 0.74 & 0.391 \\
\hline Nonvegetarian & 160 & 33.2 & 322 & 66.8 & & \\
\hline \multicolumn{7}{|c|}{ 3. Main source of drinking water } \\
\hline Pipe & 108 & 29.0 & 264 & 71.0 & 13.12 & 0.000 \\
\hline Others & 62 & 46.3 & 72 & 53.7 & & \\
\hline \multicolumn{7}{|c|}{ 4. Type of water used } \\
\hline Boiled water & 141 & 33.3 & 283 & 66.7 & 0.14 & 0.771 \\
\hline Unboiled water & 29 & 35.4 & 53 & 64.6 & & \\
\hline \multicolumn{7}{|c|}{ 5. Daily consumption of water in glasses } \\
\hline Upto 5 & 41 & 32.3 & 86 & 67.7 & 1.94 & 0.378 \\
\hline $6-9$ & 84 & 36.7 & 145 & 63.3 & & \\
\hline$>10$ & 45 & 30.0 & 105 & 70.0 & & \\
\hline \multicolumn{7}{|c|}{ 6. Use of black tea } \\
\hline Daily & 85 & 33.3 & 170 & 66.7 & 0.005 & 0.997 \\
\hline Occasionally & 59 & 33.5 & 117 & 66.5 & & \\
\hline Never & 26 & 34.7 & 49 & 65.3 & & \\
\hline \multicolumn{7}{|c|}{ 7. Use of sea fish } \\
\hline Daily & 47 & 30.9 & 105 & 69.1 & 0.79 & 0.673 \\
\hline Occasionally & 113 & 35.0 & 210 & 65.0 & & \\
\hline Never & 10 & 32.3 & 21 & 67.7 & & \\
\hline \multicolumn{7}{|c|}{ 8. Use of dry fish } \\
\hline Daily & 6 & 42.9 & 8 & 57.1 & 0.84 & 0.657 \\
\hline Occasionally & 130 & 33.9 & 253 & 66.1 & & \\
\hline Never & 34 & 31.2 & 75 & 68.8 & & \\
\hline \multicolumn{7}{|c|}{ 9. Use of citrus fruits } \\
\hline Daily & 19 & 31.7 & 41 & 68.3 & 0.29 & 0.866 \\
\hline Occasionally & 147 & 33.7 & 289 & 66.3 & & \\
\hline Never & 4 & 40.0 & 6 & 60.0 & & \\
\hline
\end{tabular}

Table 9 : Association between dental fluorosis and main source of drinking water

\begin{tabular}{|c|c|c|c|c|c|c|c|}
\hline \multicolumn{8}{|l|}{ Dental fluorosis } \\
\hline Source of water & Nil & Grade I & Grade II & Grade I II & All grades & \multirow[t]{3}{*}{$\chi^{2}$} & \multirow[t]{3}{*}{$\mathrm{P}$} \\
\hline Pipe & $29 \%$ & $13.2 \%$ & $45.2 \%$ & $12.6 \%$ & $71 \%$ & & \\
\hline Borewell & $46 \%$ & $20 \%$ & $32 \%$ & $2 \%$ & $54 \%$ & & \\
\hline Pond & $100 \%$ & 0 & 0 & 0 & 0 & \multirow[t]{2}{*}{29.30} & \multirow[t]{2}{*}{.004} \\
\hline Others & $32.3 \%$ & $22.6 \%$ & $35.5 \%$ & $9.7 \%$ & $67.7 \%$ & & \\
\hline
\end{tabular}

Chart 1: Prevalence of dental fluorosis among Group A

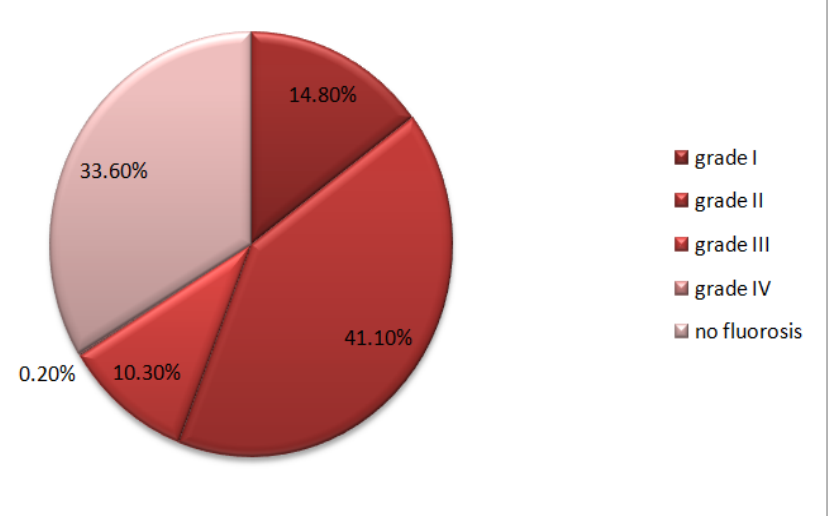




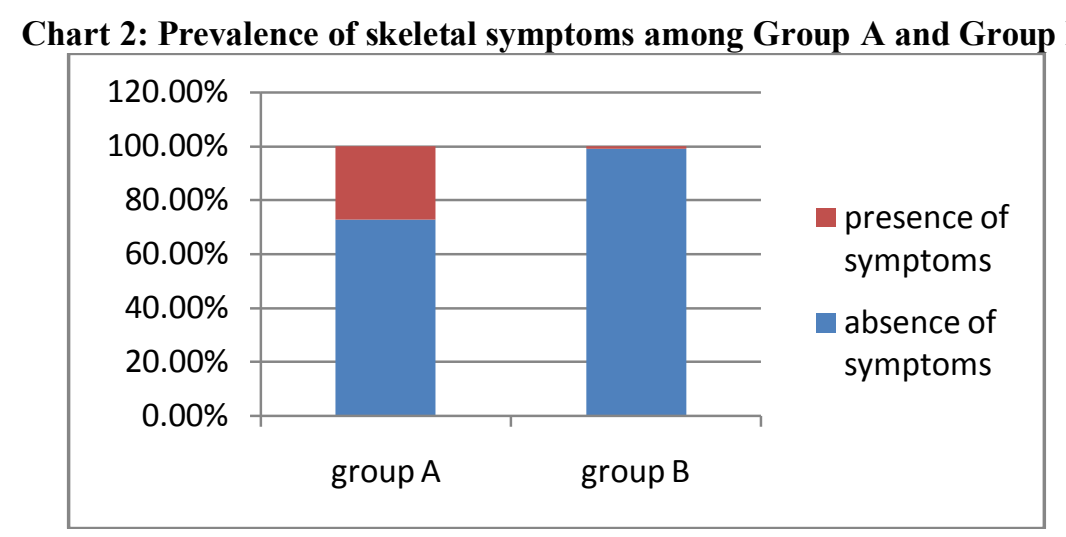

\section{References}

[1]. Ainsworth N.J. (1933): Mottled teeth Br. Dent J 60: 233-250.

[2]. Bardsen A, Bjorvatn K. Dental fluorosis among persons exposed to high- and low-fluoride drinking water in western Norway. Community Dentistry and Oral Epidemiology; 1999: 27: 25-29

[3]. Dental Council of India. National oral health survey and fluoride mapping 2002-2003Kerala. Dental Council of India: New Delhi; 2004.9-267

[4]. Bardsen et al. Risk periods in the development of dental fluorosis; clinic.oral.investig.1998:2.155-160.

[5]. Sudhir KM, Prashant GM, Subba Reddy VV, Mohandas U, Chandu GN. Prevalence and severity of dental fluorosis among 13 - to 15-year-old school children of an area known for endemic al fluorosis: Nalgonda district of Andhra Pradesh.J Indian Soc Pedod Prev Dent; 2009: 27(4):190-6.

[6]. Susheela AK (1993): Prevention and control of fluorosis in India. Rajiv Gandhi National Drinking Water Mission, Ministry of Rural Development, New Delhi.

[7]. Gopalakrishnan.P,Vasan.R.S,Sarma,P.S,Nair.K.S,Thankappan,K.R. : Prevalence of dental fluorosis and associated risk factors in Alappuzha district, Kerala. Natl :Med J India ; 1999.12:99-103.

[8]. Chandrashekar J, Anuradha K: Prevalence of dentalfluorosis in rural areas of Davangere, India.: Int Dent J; 2004 Oct;54:235-99

[9]. Dean HT (1936): Chronic endemic dental fluorosis, Jour. Am. Dent. Assoc. 107: 1269-1272

[10]. Baskaradoss JK, Clement RB, Narayanan A. ): Prevalence of dental fluorosis and associated risk factors in 11-15 year old school children of Kanyakumari District, Tamilnadu, India: a cross sectional survey. Indian J Dent Res. 2008.19 (4):297-303.

[11]. Amarjit Singh \& Jolly S.S): Endemic fluorosis (an epidemiological biochemical and clinical study in the Bhatinda district of Punjab). Ind J. Med. Res. , 1962: 50: 387-398

[12]. Choubisa SL, Choubisa DK, Joshi SC, Choubisa L). Fluorosis in some tribal villages of Dungarpur district of Rajasthan, India. Fluoride Research; 1997: 30(4):223-8.

[13]. Dean et al : Dental fluorosis. Its use as a biomarker. Several epidemiological studies, beginning with those of Dean and co workers in the 1940 s. Adv. Dent. Res. ; 1994: 8; 105-110.

[14]. Susheela AK. : State of Art report on the extent of fluoride in drinking water and the resulting endemicity in India, 1999: UNICEF Report.

[15]. Susheela AK) :Fluorosis management programme in India. Curr Sci ; .1999:77(10):1250-6. 